\title{
ENTERPRISE RISK ASSESSMENT FOR INNOVATION TALENTS
}

\author{
C. CHEN \& X. ZHANG \\ College of Business Administration, Huaqiao University, China.
}

\begin{abstract}
Innovation talents bring risks as well as profits for companies. The particularity of the risk identification of innovation talents lies in talents' individual differences and corresponding risks. This paper summarizes the characteristics of the enterprise risk assessment system of innovation talent basing its meanings and different perspectives. Including talent selection, talent strategies, and human resources management, innovation-organization atmosphere, the external eco-environment for the development of innovation talents, the paper analyzes the special influencing factors of the enterprise risk assessment system of innovation talents and sets up the risk assessment system by means of Analytic Hierarchy Process.
\end{abstract}

Keywords: Analytic hierarchy process, enterprise, innovation talents, risk assessment.

\section{INTRODUCTION}

As innovative entities, enterprises work as the terminal platform to combine knowledge, technology and innovation, and innovation talents are the core of this platform. Innovation talents are defined as a group of talents of highly innovative spirit, with strongly innovative ability and superb work performance in human resources. The relationship between talents and enterprises' core competitiveness has already risen to a strategic level. American socialist, W. Schultz put forward Human Capital Theory in 1960, in which talents were regarded as the largest intangible properties, and human quality and knowledge investment would determine the future of human beings to some extent. The forefather of Creative Economy, Florida, declares that, in the creative ages, human capital clusters are more important than enterprise clusters [1]. However, several facts, such as brain drain, business secret leakage, show that talents take risks as well as create wealth. Therefore, how to avoid or decrease the risks of innovation talents is the key part of innovation talents management. The risks of innovation talents include the tangible or intangible potential risks, largely due to talents' individual differences and the poor management of human resources. The risk assessment for innovation talents works to identify, analyze and foresee the certain relevant risks, and provide corresponding measures to avoid risks or minimize the loss from risks. The research on innovation talents at home and abroad merely focuses on the definition, characteristics, identification, classification, and strategic significance of innovation talents, while they fail to cover the risk assessment for innovation talents [2]. The present studies tend to identify the risks aroused by innovation talents and put forward corresponding assessment methods based on the working procedure of human resources [3], working environment [4] and the structure of workforce [5,6]. It also covers the risks of brain drain and the use of talents. The most mature risk assessment models of brain drain are March-Simon model (1958), Price-Mueller (1981) and Mobley's Intermediate Chain (1991). These models conclude four variables related to the flow of talents, that is, environment variable, individual variable, structure variable and procedure variable [7]. Droege empirically analyzes that the social structure of enterprise determines the loss degree of implicit knowledge in talents flow [8]. Irene summarizes that high-risk preference indeed causes high resignation intention of talents. The staff 
flow decision is shaped by both internal and external relation networks [9]. Guangyu adopts Fussy Comprehensive Assessment to analyze the risk management framework of innovation talents loss in hi-tech enterprises [10]. Wang sets up the risk assessment system and decision support system by factor analysis [4]. Talent risk mainly refers to low working spirit or the poor performance of talents due to various factors when talents are working. Moldenhauer-Salazar (2008) researched into the innovation failure of SUNRAY, and he found out that the reason was getting out of control for innovation team when annexing JavaStation, the team members of the merged enterprises brought inappropriate culture into research institution, which kept back the high working spirit of staff [11]. Zhang and Chandrasekar [12] observed chief executives from the organizational perspective and found that these chief executives worked well at the beginning but felt depressed toward the end. The relevant factors include opportunity cost loss due to the failure in achieving the goals, re-recruitment cost, and low spirit when the staff face failure [12]. Suzanne Ross [13] found that many factors can lead to management dilemma when she further defined manager dilemma. It is essentially significant to analyze the manager dilemma from their personal qualities, such as $\mathrm{EQ}$, personality and out-of-group behavior deficiency, whereas the good partnership and working network is useful to improve working efficiency and reduce manager dilemma. Enterprise consists of human factors and complicated social systems. The subjective individual ability and the complexity of social environment are the roots of the risks for innovation talents. Compared with the common human resources, innovation talents are characterized by their rarity, mobility and timeliness. Because of the sensitivity to talent management policy and environment, innovation talents have been faced with more risks. It is important to provide the scientific evidence for enterprise risk management through the proper risk assessment for innovation talents. The paper gives research on innovation talents by combining several perspectives to identify the risks of innovation talents and set up its risk assessment model. The paper also uses the Analytic Hierarchy Process (AHP) to analyze the index weights of the risks of innovation talents and build up the comprehensive risk assessment system of innovation talents.

\section{THE DEFINITION AND RISK IDENTIFICATION OF ENTERPRISE INNOVATION TALENTS}

\subsection{The definition of innovation talents in enterprise}

There are three definitions of innovation talents in China. The first definition emphasizes the properties of innovation talents, including innovative spirits, innovative ability and innovative personality. The second sorted out talents who make greater contributions to society according to the innovative fruit and output. The last one combines the first two definitions [14] Overseas scholars stress innovative thinking and innovative personality from psychological perspective to define innovation talents. However, there is few literature about the concept of innovation talents. American Innovative Journal (2006) defined innovation talents as follows: talents are the persons who are able to use their wisdom and knowledge to carry out novel and new approaches on innovative craftwork, products and achieve new research output [15]. The paper regards innovation talents as those who are endowed with knowledge structure and certain properties close to enterprises and gifted with innovative spirits, and who can make positive contributions to enterprises. Innovation talents exist in any job, only if they possess basic innovative properties or yield innovative fruit. According to China's Guidance of Hi-Tech Enterprise to Certification Management (2008), Cheng (2009) classified hi-tech 
enterprise talents into risk entrepreneurs, managers, technicians, salesmen and producing workers [5]. The article suggests that enterprise innovation talents should be grouped into professional technicians, researchers, managers and so on.

\subsection{The risk identification of innovation talents}

The risk identification is the premise of the risk assessment, while the risk analysis process delimits the scale of risk assessment. Apart from the general factors, innovation talents take special risks due to individual differences and their corresponding risk outburst. The risk identification can be illustrated as given in the following sections.

\subsubsection{Talent selection}

Different strategies must attract and recruit the suitable talents. For innovation-oriented enterprises, the key is how to identify the innovation strategies of company and keep the staff working in a highly efficient and skillful way. Canavan et al. [16] suggests that innovation-oriented service companies should realize the fact that their profit-increasing strategies should depend on the members who help to achieve the company goals. The enterprise strategies can be divided into the strategies of product differentiation and sophisticated strategies of competition, and talents should possess the corresponding properties of two strategies. Talents have different performances when they are varied at the staff career expectation (career orientation/study opportunity), motivation (promotion/profession location), and professional proficiency (all-round persons/technical expertise) [16].

The fussiness of innovative property hinders the identification of innovative property and innovation talents selection. The talent introduction leads to adverse selection, ethics risk and efficiency problems because of information asymmetry. The appropriate channels and approaches of talent selection guarantee the match between talents and jobs. It is necessary to bring the channel and approach of talent selection into the talent risk assessment model. The initial step to guarantee the match between talents and posts is to strategically select those who obtain certain kinds of innovative property in staff recruitment.

\subsubsection{Enterprise talent strategy and human resources management}

Talent strategy makes the enterprise innovative strategy work well. Talent strategy embodies the focus of companies' talent concept and guarantees the realization of innovation practice in the company. Innovation enterprises resort to the proper human resource policies to attract influential staff. For example, Google Company introduces the concepts of freedom and innovation into talent management, which determines the company attraction to talents to some extent. The behaviors of talents are the foundation of group working efficiency, whereas human resource management (HRM) works to coordinate individual behaviors and company operation. In the 1980s, Devanna and other researchers studied the idea of building the longterm core competitiveness, and introduced the concept of StrategicHRM (SHRM), which indicated the match of human resources management with competitive strategies at an organizational level to promote organizational performance. Wright et al. [17] empirically proved a significant relationship between SHRM and company performance, and they proposed the best practices approach. However, human resources management by contingency approach claimed that the so-called optimal human resources practice was not universally acceptable, so the specific human resources management practice may yield a better performance under specific organization strategies. Verano-Tacoronte and Melián-González [18] studied sales team performance to assert that HRM (especially the best HRM practices approach) has a 
positive impact on team performance, taking uncertainty and human resources risk behaviors as medium variables. In other words, uncertainty and human resources risk behavior affects organizational performance, so working for the best HRM practices approach is helpful to reduce organizational risks and improve its performance. Innovation-oriented enterprises face more environment uncertainty and human resource risks, so the best HRM practices approach is imperative. As for innovation talents, the best practices approach covers compensation system and performance management system. The total compensation management system includes material incentives and mental incentives, the performance brought by job features and organization characteristics. Innovation talents should get the balanced approvals from material and mental incentives. The strategic performance management system not only improves the efficiency of motivation plan, but also keeps the pursuit of working achievements and the realization of the participation in management.

\subsubsection{Innovation organization environment}

Organization environment influences organization innovation. Organization environment can be seen as an organization property, which is realized by organization members and keeps stimulating the organization members' innovation behaviors. Galpin and Whittington [19] discover that innovation-oriented companies have a high-level reliance on innovation talents, and companies grow with their unique creativity and styles relying on innovation talents. The superior power over their subordinates in a company can be showed mainly by their creativity and persuasion, not from their position. Companies attract innovation talents and appraise them to yield high output. That is to say, companies are creating a harmonious atmosphere becomes working environment. Google-styled cultural innovation management is called Drucker's ideality, which suggests that a working environment should demonstrate the social values of human beings, such as opportunity, social communication, recognition and personal satisfaction, not merely business values such as capitals and efficiency. Culture doctrines, such as 'adventures encouragement and failure toleration', 'the belief of innovation importance' and 'the will to communicate', give a positive impact on enterprise innovation performance [20].

Innovation organization environment needs diverse, flexible enterprise policies to explore the optimal human resources practice. It facilitates to create innovative environment in an organization. Broughton [21] shows that diverse enterprise policies quickly attract talents. The diverse management also enhances enterprises to upgrade themselves [21]. Also, innovation teamwork helps reduce the risks of innovation talents. Enterprises should make great efforts to cultivate the organizational commitment of innovation talents and establish innovation team power to accumulate innovative achievements and innovative thoughts for enterprises, and remove the risks from individual behaviors of innovation talents.

\subsubsection{The innovation-oriented physical eco-environment}

Scarcity, ability and timeliness of innovation talents claim the fact that external environment of organization is one of the sensitive risk elements of innovation talents. For innovation talents, the proper ecological environment includes the comfortable working and living environment and the advantageous social environment for innovative achievements. Harvey [22] suggests that social elements and lifestyles become the critical influencing factors for topclass sport players to move to other countries. Experts immigrating overseas have several motivations, such as fresh lifestyle, good children-nurture environments, better career opportunities and curiosity of new environment. At the early stage, they focus on job opportunities, 
but they pay attention to family and lifestyle at the later stage. Different state policies attract expert immigrants, because these experts are fond of carefree environments, opportunities and the optimal development opportunities.

The famous Florida's 'three Ts' theory emphasizes the triangle relationship among talents, technology and tolerance, which can be seen like this: tolerance attracts talents, which, in turn, creates technology. Therefore, tolerant, diverse open, humane environments and social values are the indispensable conditions to attract innovation talents. In creative stage, human environment matters more than business values. Innovation talents think highly of such values as diversity, tolerance and the ability to be the authority.

External law maturity and execution improves the protection of innovative achievements and reduce business secret leakage risk of innovation talents' flow. Xu [23] point out that the flow of talents has been the main means of business secret leakage, and it is necessary to set up and complete the appropriate system to prohibit vicious business competition as Hawkins and Hai [24] put forward 'copyright is currency'. Innovative economy needs new policy to make sure that innovative market's value can be freely achieved.

\section{THE ENTERPRISE'S RISK ASSESSMENT MODEL FOR INNOVATION TALENTS}

\subsection{The enterprise's risk identification model for innovation talents}

To sum up, there are three main sections affecting the risks of innovation talents, namely, the match between companies and talents at the introductory stage, the use process of talents and brain drain toward the end. The main influence factors of talent introduction stage is recruitment channels and selection means; and the main factors in the use process is the concept of talent, the best HRM practices approach (including total compensation system and strategic performance system), the innovative atmosphere, diverse and flexible policies. The factors of brain drain come from internal and external company factor. The internal factors including HRM practice, talents use efficiency and talent concept affect the working efficiency of talents in companies and then cause brain drain, whereas the external factors consist of tolerance and open and humane social environment and values, and law maturity and execution. Figure 1 shows the interwoven relationship of the factors in the enterprise's risk identification model for innovation talents.

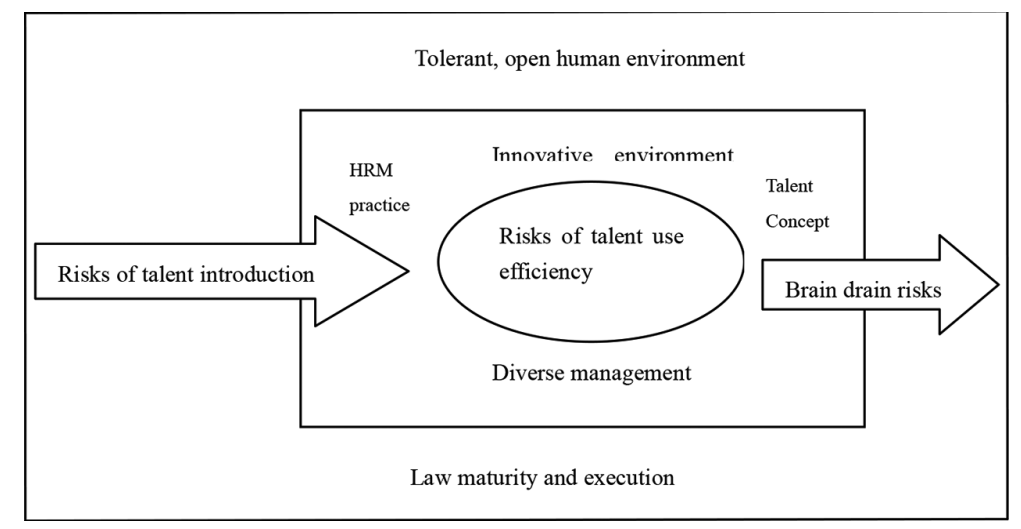

Figure 1: The enterprise's risk identification model for innovation talents. 
3.2 Defining the weights of the factors in the enterprise's risk assessment model for innovation talents

Based on risk analysis, the weights of factors in the enterprise's risk assessment model of innovation talents should be selected and defined in the proper means in order to estimate risk rates or loss of risks. In view of complexity and fussiness of factors of the enterprise's risk assessment model for innovation talents, the paper adopts the AHP to define it.

AHP is a decision-making method by which decision makers can judge their goals and simplify some complicated decision-making problems with multiple criteria or no structural characteristics according to their experiences [25]. So AHP is a simple, practical approach to weigh of the factors of the enterprise's risk assessment model for innovation talents. The basic procedure of AHP is to set up the diagram of AHP of the enterprise's risk assessment model for innovation talents, form judgment matrixes, calculate weight vectors and to evaluate the universal function of decision making.

\subsubsection{Set up the index system of the enterprise's risk assessment model} for innovation talents

The index system in AHP can be divided into goal level, standard level and index level according to the subjects of decision making. Based on the above analysis, we can draw the ascending hierarchic analysis structure of the enterprise's risk assessment for innovation talents, which can be seen in Table 1.

\subsubsection{Formulate judgment matrixes}

Judgment matrixes show the interrelationship between all factors, in which the factors at a level is set compared with the factors at a higher level according to their importance. B level can be shown as $\mathrm{B}_{1}, \mathrm{~B}_{2}, \mathrm{~B}_{3}$. $\mathrm{C}$ level can be shown as $\mathrm{C}_{11}, \mathrm{C}_{12}, \mathrm{C}_{21} \ldots \ldots \mathrm{C}_{32}$. The basic unit $\mathrm{a}_{\mathrm{ij}}$ in

Table 1: The ascending hierarchic analysis structure of the enterprise's risk assessment for innovation talents.

\begin{tabular}{lll}
\hline Goal level A & Standard level B & Index Level C \\
\hline & $\mathrm{B}_{1}$ : Risk of talent introduction & $\mathrm{C}_{11}:$ Talent selection \\
$\begin{array}{l}\text { Enterprise risk } \\
\text { assessment for } \\
\text { innovation talents }\end{array}$ & $\mathrm{B}_{2}$ : Risks of talent use efficiency & $\mathrm{C}_{21}:$ : Tecruitment channel \\
& $\mathrm{C}_{22}:$ Salary system \\
& $\mathrm{C}_{23}:$ Performance Management \\
& $\mathrm{C}_{24}:$ Innovation atmosphere \\
& $\mathrm{C}_{25}:$ Management flexibility \\
& $\mathrm{C}_{31}:$ Tolerant and open society \\
& $\mathrm{C}_{32}:$ Law efficiency \\
\hline
\end{tabular}


judgment matrix is obtained by the Santy's $1-9$ degrees marking methods. When $C_{i}$ and $C_{j}$ are equally important is $1 ; C_{i}$ slightly more important than $C_{j}$ is $3 ; C_{i}$ more important than $C_{j}$ is 5; when $C_{i}$ very important than $C_{j}$ is $7 ; C_{i}$ absolutely important than $C_{j}$ is taken as 9 . On the other hand, are $1 / 3 ; 1 / 5 ; 1 / 7 ; 1 / 9 ; 2,4,6,8$ is the intermediate state between the two elements of the corresponding judgment scale. Therefore, $C_{i i}=1, C_{i j}>0, C_{i j}=1 / C_{j i}$. We asked five experienced expert opinions to give the relative importance with grade evaluation. And combine their scores, get the following judgment matrix as Tables 2-5.

\subsection{Monolayer ordering, total order and consistency check}

Using the square root method calculates the maximum weight for each judgment matrix. We get eigenvalue $\lambda_{\max }$ and eigenvector $\omega$, which meet $\mathrm{C} \omega=\lambda_{\max } \omega . \omega_{i}$ is the weight of index $\mathrm{C}_{\mathrm{i}}$ $(\mathrm{i}=1,2, \ldots, \mathrm{n})$. If $\mathrm{CR}<0.10$, assume that the consistency of the matrix is satisfactory; otherwise, it need to readjust the matrix until satisfaction. We used the AHP of Tianjin University

Table 2: A-B judgment matrix.

\begin{tabular}{llll}
\hline $\mathrm{A}$ & $\mathrm{B}_{1}$ & $\mathrm{~B}_{2}$ & $\mathrm{~B}_{3}$ \\
\hline $\mathrm{B}_{1}$ & 1 & $1 / 3$ & 2 \\
$\mathrm{~B}_{2}$ & 3 & 1 & 5 \\
$\mathrm{~B}_{3}$ & $1 / 2$ & $1 / 5$ & 1 \\
\hline
\end{tabular}

Table 3: $\mathrm{B}_{1}-\mathrm{C}$ judgment matrix.

\begin{tabular}{lll}
$\mathrm{B}_{1}$ & $\mathrm{C}_{11}$ & $\mathrm{C}_{12}$ \\
\hline $\mathrm{C}_{11}$ & 1 & $1 / 4$ \\
$\mathrm{C}_{12}$ & 4 & 1 \\
\hline
\end{tabular}

Table 4: $\mathrm{B}_{2}-\mathrm{C}$ judgment matrix.

\begin{tabular}{llllll}
\hline $\mathrm{B}_{2}$ & $\mathrm{C}_{21}$ & $\mathrm{C}_{22}$ & $\mathrm{C}_{23}$ & $\mathrm{C}_{24}$ & $\mathrm{C}_{25}$ \\
\hline $\mathrm{C}_{21}$ & 1 & $1 / 5$ & $1 / 5$ & $1 / 7$ & 2 \\
$\mathrm{C}_{22}$ & 5 & 1 & 1 & $1 / 2$ & 3 \\
$\mathrm{C}_{23}$ & 5 & 1 & 1 & $1 / 2$ & 2 \\
$\mathrm{C}_{24}$ & 7 & 2 & 2 & 1 & 3 \\
$\mathrm{C}_{25}$ & $1 / 2$ & $1 / 3$ & $1 / 2$ & $1 / 3$ & 1 \\
\hline
\end{tabular}

Table 5: $\mathrm{B}_{3}-\mathrm{C}$ judgment matrix.

\begin{tabular}{lll}
\hline $\mathrm{B}_{3}$ & $\mathrm{C}_{31}$ & $\mathrm{C}_{32}$ \\
\hline $\mathrm{C}_{31}$ & 1 & 3 \\
$\mathrm{C}_{32}$ & $1 / 3$ & 1 \\
\hline
\end{tabular}


software and obtained monolayer ordering and the level of total order and consistency check of the results as given in Tables 6 and 7 .

\section{CONCLUSION AND SUGGESTIONS}

The article analyzes and sorts out factors of enterprise risk assessment of innovation talents and sets up the risk factor assessment system involving nine factors. The enterprise risk assessment model of innovation talents enriches the research subjects of enterprise risk assessment of innovation talents. The results show the innovation atmosphere's weight (0.254) is in the first $(0.254)$, recruitment channel is the second (0.184). Salary system is the third (0.156), and performance management in forth (0.144), Tolerant and open society surroundings in fifth (0.092). These provide useful guidance to the enterprises risk management for innovative talents. The most important task is to creating an internal innovation atmosphere

Table 6: Monolayer ordering and consistency check results.

\begin{tabular}{lllll}
\hline & $\mathrm{A}-\mathrm{B}$ & $\mathrm{B}_{1}-\mathrm{C}$ & $\mathrm{B}_{2}-\mathrm{C}$ & $\mathrm{B}_{3}-\mathrm{C}$ \\
\cline { 2 - 5 }$\lambda_{\max }$ & 3.004 & 2.00 & 5.308 & 2.00 \\
\hline$\omega=\left(\omega_{1}, \omega_{2}, \ldots, \omega_{\mathrm{n}}\right)$ & $\begin{array}{c}(0.230,0.648, \\
0.122)\end{array}$ & $(0.200,0.800)$ & $(0.066,0.024$, & $(0.750,0.250)$ \\
& & & $0.233,0.391$, & \\
$\mathrm{CI}$ & 0.002 & 0.000 & $0.079)$ & \\
$\mathrm{RI}$ & 0.580 & 0.000 & 1.120 & 0.000 \\
$\mathrm{CR}$ & 0.003 & 0.000 & 0.069 & 0.001 \\
Consistency & Satisfactory & Satisfactory & Satisfactory & Satisfactory \\
\multicolumn{1}{c}{ check results } & consistency & consistency & consistency & consistency \\
\hline
\end{tabular}

Table 7: Total order and consistency check.

\begin{tabular}{lcccc}
\hline & \multicolumn{3}{c}{ Level B } \\
\cline { 2 - 4 } & $\mathrm{B}_{1}$ & $\mathrm{~B}_{2}$ & $\mathrm{~B}_{3}$ & \\
\cline { 2 - 4 } Level C & 0.230 & 0.648 & 0.122 & $\begin{array}{c}\text { Level C } \\
\text { Weight }\end{array}$ \\
\hline $\mathrm{C}_{11}:$ Talent selection & 0.200 & & & 0.046 \\
$\mathrm{C}_{12}:$ Recruitment channel & 0.800 & & & 0.184 \\
$\mathrm{C}_{21}:$ Talent concept & & 0.066 & & 0.043 \\
$\mathrm{C}_{22}:$ Salary system & & 0.024 & & 0.156 \\
$\mathrm{C}_{23}$ : Performance management & & 0.233 & & 0.144 \\
$\mathrm{C}_{24}:$ Innovation atmosphere & & 0.391 & & 0.254 \\
$\mathrm{C}_{25}$ : Management flexibility & & 0.079 & & 0.051 \\
$\mathrm{C}_{31}$ : Tolerant and open society & & & 0.750 & 0.092 \\
$\mathrm{C}_{32}:$ Law efficiency & & & 0.250 & 0.031 \\
Consistency check results & $\mathrm{CI}=0.050, \mathrm{RI}=0.726, \mathrm{CR}=0.069$ & \\
\hline
\end{tabular}


to prevent and control the risk. Then, using recruitment channel and tool to select the creative talents is also a good way to reduce the risk. The nearly weight of performance management and compensation management again proves that they cannot be separated which is indispensable and important in talent management. External factors in the environment are also worthy of attention that the government should create a tolerant and open society to encourage creativity.

\section{ACKNOWLEDGMENT}

Fund Project: 'project supported by the fundamental research funds for the central universities philosophy and social science of Huaqiao University young scholars growth project' (12SKGC-QT02).

\section{REFERENCES}

[1] Florida, R., The Rise of Creative Class, Citic Press, 2007.

[2] Meimei, Z. \& Jinlian, L., A survey on innovative talent study at home and abroad. Talent Exportation, (08), pp. 11-14, 2009.

[3] Hongbo, Z., Risk management of enterprise talents based on security of talents. Journal of China's Security Science, (11), pp. 21-24, 2004.

[4] Xin, W., Study on talent loss in hi-tech enterprise based on risk theory. Soft Science, (12), pp. 141-144, 2008.

[5] Ziji, C., An analysis on the risk of hi-tech enterprise talents. Zhen Jiang Journal, (1), pp. 39-42, 2001.

[6] Dechang, L., Yong, F. \& Yang, G., The risk management of salesmen. Enterprise Management, (11), pp. 92-94, 2006.

[7] Hom, P.W. \& Kinicki, A.J., Toward a greater understanding of how dissatisfaction drives employee turnover. The Academy of Management Journal, 44(5), pp. 975-987, 2001. doi: http://dx.doi.org/10.2307/3069441

[8] Droege, S.B. \& Hoobler, J.M., Employee turnover and tacit knowledge diffusion: a network perspective. Journal of Management Issues, 15(1), pp. 50-64, 2003.

[9] Chow, I.H.S., Ng, I. \& Gong, Y., Risk-taking and relational perspective on turnover intentions. The International Journal of Human Resource Management, 23(4), pp. 779-792, 2012. doi: http://dx.doi.org/10.1080/09585192.2011.561249

[10] Guangyu, Z., Huajun, L. \& Depeng, Z., Risk Management on knowledge employees turnover in high-tech firms-based on fuzzy comprehensive evaluation. Information Management, Innovation Management and Industrial Engineering, (3), pp. 1-4, 2008. doi: http://dx.doi.org/10.1109/iciii.2008.174

[11] Molden hauer-Salazar, J. \& Valikangas, L., Sun Ray's struggle to overcome innovation trauma. Strategy \& Leadership, 23(3), pp. 654-667, 2008. doi: http://dx.doi. org/10.1108/10878570810870749

[12] Zhang, Y. \& Chandrasekar, N.A., When building strength is not enough: an exploration of derailment potential and leadership strength. Journal of General Management, 35(3), pp. 195-211, 2011.

[13] Ross, S., Talent derailment: a multi-dimensional perspective for understanding talent. Industrial and Commercial Training, 45(1), pp. 168-182, 2013. doi: http://dx.doi. org/10.1108/00197851311296656 
[14] Dasheng, L., Qingyan, J. \& Yaomei, K., The joint running school of research, study and production and innovation talents nurture. Higher Education Exploration, (5), pp. 60-62, 2007.

[15] Wei, L., Study on Recognizing Innovation Talents, Jilin University, 2012.

[16] Canavan, D., Sharkey Scott, P. \& Mangematin, V., Creative professional service firms PSF: aligning strategy and talent, Journal of Business Strategy, 34(3), pp. 24-32, 2013.

[17] Wright, P.M., Gardner, T. \& Moynihan, L.M., The impact of HR practices on the performance of business units. Human Resource Management Journal, 13(3), pp. 16, 21-36, 2003. doi: http://dx.doi.org/10.1111/j.1748-8583.2003.tb00096.x

[18] Verano-Tacoronte, D. \& Melián-González, S., Human resources control systems and performance: the role of uncertainty and risk propensity. International Journal of Manpower, 29(2), pp. 161-187, 2008. doi: http://dx.doi.org/10.1108/01437720810872712

[19] Galpin, T. \& Whittington, J.L., Sustainability leadership: from strategy to results. Journal of Business Strategy, 33(4), pp. 40-48, 2012. doi: http://dx.doi.org/10.1108/ 02756661211242690

[20] Jinying, L., An empirical study on innovative culture property and enterprise innovative performance based on the study on China's Photoelectron enterprises. Science Development and Decision Making, (7), pp. 85-89, 2010.

[21] Broughton, A., Reaping benefits from diversity. Strategic HR Review, 7(5), pp. 5-10, 2008. doi: http://dx.doi.org/10.1108/14754390810893035

[22] Harvey, W., Victory can be yours in the global war for Talent. Human Management International Digest, 21(1), pp. 37-40, 2013. doi: http://dx.doi.org/10.1108/ 09670731311296519

[23] Xu, H., Study on business secret protection in hi-tech enterprise talent flow. Study on Technology Management, (20), pp. 172-174, 2012.

[24] Howkins, J. \& Hai, L., Creative Ecology: Thinking Here is the Real Career (trans.), Beijing Joint Presshouse, 2011.

[25] Shihai, T., Management Logistics, Science Presshouse, 2011. 